\title{
An ER-associated miRNA signature predicts prognosis in ER-positive breast cancer
}

\author{
Xin Zhou ${ }^{1+}$, Xiaping Wang ${ }^{3+}$, Zebo Huang ${ }^{1+}$, Lei Xu ${ }^{4}$, Wei Zhu ${ }^{1 *}$ and Ping Liu ${ }^{1,2^{*}}$
}

\begin{abstract}
Background: Breast cancer patients with positive estrogen receptor (ER) have a better prognosis. However, no prognostic miRNA signature was reported in the ER-positive breast cancer. The aim of the study was to identify and assess the prognostic significance of a miRNA signature in ER-positive breast cancer.

Methods: Two cohorts from The Cancer Genome Atlas (TCGA) dataset were used as training ( $n=596)$ and testing set $(n=319)$. Differential expression profiling was identified in the training set. And the prognostic value of the miRNA signature was then assessed in the two cohorts.

Results: A total of 14 miRNAs were observed to be associated with the status of ER by significance analysis of microarrays (SAM) in the training set. Patients were characterized as high score or low score group according to the calculated risk scores from each miRNA. And patients in high score group had worse overall survival compared with those in low score group both in the training and testing set.
\end{abstract}

Conclusions: Our study revealed a miRNA signature including 14 miRNAs associated with ER status which could act as a prognostic marker in ER-positive breast cancer.

Keywords: Breast cancer, ER status, miRNA signature, prognosis

\section{Introduction}

Breast cancer is a heterogeneous disease that comprises a range of subgroups with diverse clinical behaviors and responses to treatment [1]. Many breast-cancer-related genes have been investigated to explore the molecular mechanism of carcinogenesis and diverse clinical outcome of the disease [2-6]. Among them, some specific genes such as estrogen receptor (ER) [7], progesterone receptor (PR) [8] and human epidermal growth factor receptor 2 (HER2) [9] have been used to identify different subgroups and indicate different prognostic results with different treatment modalities in the clinical. Patients with ER-positive status which account for almost $70 \%$ of breast cancer always had a better prognosis compared with those ER-negative types [10]. However, ER-positive patients also have distinct outcomes and almost $20 \%$ might relapse within 10 years after surgery [11]. Thus, there is an urgent need to identify

\footnotetext{
*Correspondence: zhuwei1983213@163.com; liu-ping@csco.org.cn ${ }^{\dagger}$ Equal contributors

'Department of Oncology, First Affiliated Hospital of Nanjing Medical University, 300 Guangzhou Road, Nanjing 210029, China

${ }^{2}$ Cancer Center of Nanjing Medical University, Nanjing 210029, China

Full list of author information is available at the end of the article
}

biomarkers that could predict prognostic outcome in patients with ER-positive breast cancer.

MicroRNAs (miRNAs) are short (approximately 22 nucleotides), single-stranded and highly conserved noncoding RNAs which could regulate almost one-third human genome based on either mRNA degradation or translational repression through base pairing with the $3^{\prime}$ untranslated region of target mRNAs at post-transcriptional level $[12,13]$. Reportedly, miRNAs play important roles in various biological processes, such as cellular development, differentiation, proliferation, angiogenesis and metabolism [14-17]. The prognostic value of miRNAs has been explored in several cancer types, such as colon cancer [18], nasopharyngeal carcinoma [19], hepatocellular carcinoma [20] and glioma [21]. To date, no prognostic miRNA signature for ER-positive breast cancer has been reported. In the present study, we used data retrieved from The Cancer Genome Atlas (TCGA, http://cancergenome. nih.gov/) and identify a miRNA signature associated with the status of ER which could act as a prognostic predicator for ER-positive patients. 


\section{Methods and materials Expression profiles}

The miRNA expression microarray data (Level 3) and corresponding clinical data for breast cancer patients were obtained from The Cancer Genome Atlas (TCGA) database (http://cancergenome.nih.gov) and Ref [22,23]. The data from two independent platforms were classified into two cohorts. The cohort with 596 patients (456 ER-positive and 140 ER-negative) undergone IlluminaHiSeq_miRNASeq platform and the smaller dataset with 319 cases (251 ERpositive and 68 ER-negative) from IlluminaGA_miRNASeq platform were used as training and validation set, respectively. As the data were obtained from TCGA, further approval by an ethics committee was not required.

\section{Statistical analysis}

The differential expression profile between ER-positive and ER-negative cases in training set was assessed by using significance analysis of microarrays (SAM) on BRB array tools package which was developed by Richard Simon and the BRB-ArrayTools Development Team [24]. And $\mathrm{P}$ value $<0.001$ with fold change $(\mathrm{FC})>2.8(\log 2 \mathrm{FC}>1.5)$ was considered significant. Risk score analysis was performed to evaluate the association of ER associated miRNA signature and overall survival of ER-positive patients. ROC curves were used to identify the optimal cutoff value for each miRNA to discriminate ER-positive from negative cases. The score for each miRNA, denoted as S, was set as 1 if the expression level was greater than the cutoff value, otherwise was set as 0 [25]. A risk score formula for predicting survival was developed based on a linear combination of the expression level multiplied regression coefficient derived from the univariate logistic regression model (B) fitted with the status of ER for each significant miRNA: Risk score $=\sum_{j-1}^{k} S_{i j} * B_{j}$. In the equation above, $\mathrm{S}_{i j}$ is the risk score for miRNA $j$ on patient $i$, and $\mathrm{B} j$ is the weight of the risk score of miRNA $j$. Patients in the training and test set were divided into high score and low score group according to the risk score. Overall survival curves for the two groups were estimated by the Kaplan-Meier methodology and compared using log-rank test.

Survival analyses were performed using SPSS version 16.0 for Windows (Statistical Package for Social Sciences, Chicago, IL). All p values were two-sided and statistical significance was defined as $\mathrm{p}<0.05$.

\section{Results}

Identification of ER associated miRNA signature

A total of 14 miRNAs were identified to be associated with ER status in the training set. Among them, 12 miRNAs (miR-135b, miR-187, miR-18a, miR-210, miR-224, miR3200, miR-452, miR-455, miR-505, miR-584, miR-9-1 and miR-9-2) were significantly up-regulated while two downregulated (miR-190b, miR-375) in ER-negative cases compared with ER-positive patients (Figure 1A). As shown in Figure $1 \mathrm{~B}$, each of the 14 miRNAs was significantly

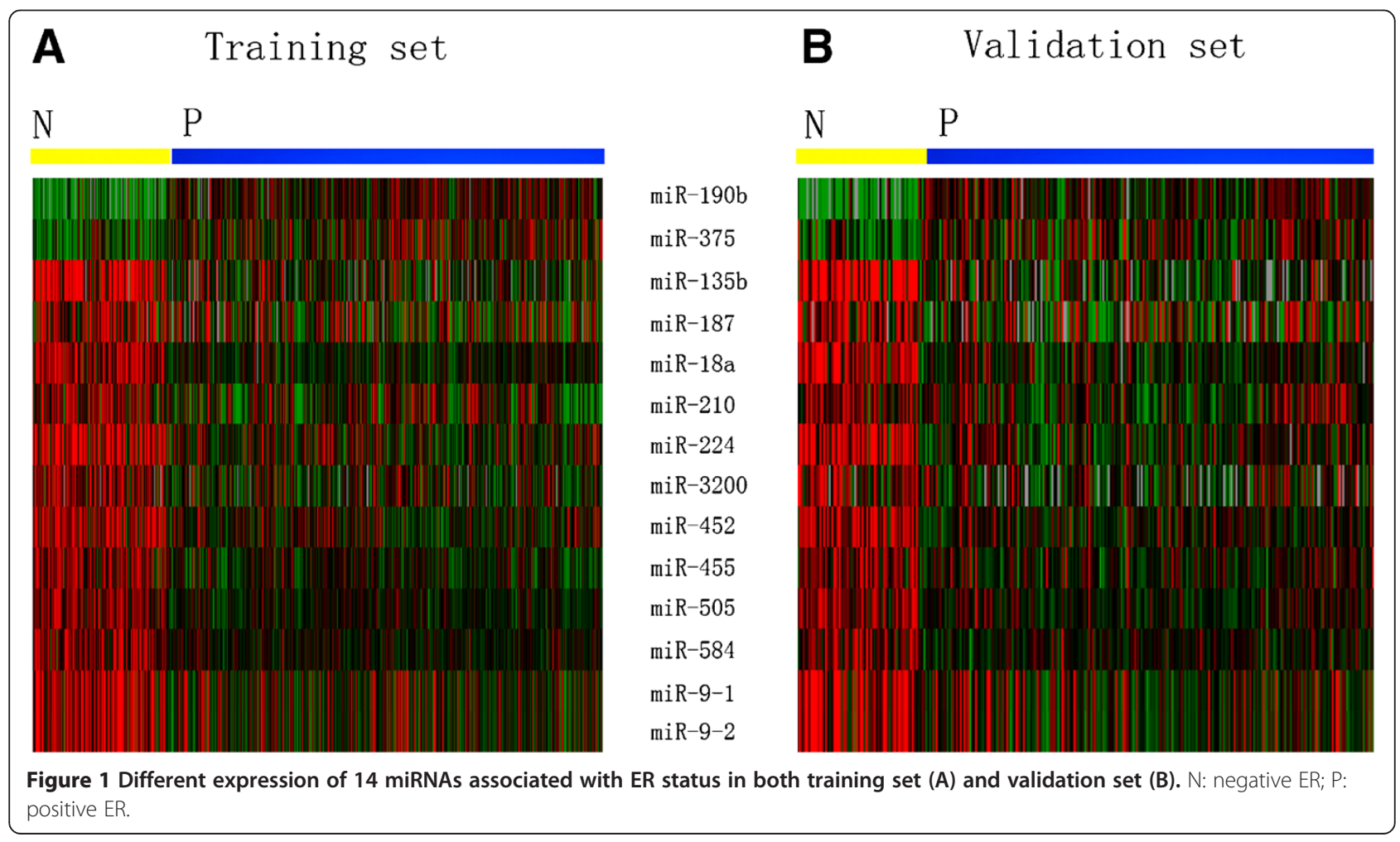


dysregulated and showed the consistent tendency according to the status of ER in the validation set.

\section{Prognostic value of ER associated miRNA signature in ER-positive patients}

By combining cases from the two cohorts, better overall survival could be found (Figure 2) in the ER-positive patients compared with ER-negative cases $(\mathrm{P}=0.019)$. To assess the prognostic value of ER associated miRNA signature, 456 ER-positive cases in training set was divided into high and low score group according to the median risk score (ROC curves for each miRNA were present in the Additional file 1: Figure S1). As shown in Figure 3A, the up-regulated miRNAs identified in ER-negative cases exhibit high expression in high score group and the downregulated miRNAs have high expression in low score group. And the patients with high score tended to have poor overall survival. Kaplan-Meier curves for the two groups were shown in Figure 3B. ER-positive patients in high score group suffered worse overall survival than those in low score group $(\mathrm{P}=0.022)$.

In the testing set, similar expression distribution of the miRNAs was found when the cutoff value for each miRNA, the same regression coefficient and cutoff value of risk score derived from the cases in the training phase was applied. And high score group is also prone to exhibiting a worse prognosis (Figure 3C). As shown in Figure 3D, prognosis of cases with high score was significantly worse than those with low score $(\mathrm{P}=0.018)$.

\section{Discussion}

Breast cancer is the most common malignancy and the second leading cause of cancer death among women worldwide [26]. Due to the distinct clinical, pathological and molecular features of the disease, the treatment, response to therapy and corresponding clinical outcome varies greatly [3]. With the help of molecular profiling and the identification of intrinsic subtypes by specific genes, breast cancer patients could benefit from appropriate treatment [27]. ER status is one of the strong factors in predicting patients' response to endocrine therapy and its determination has become a standard practice in the management of breast cancer [28]. The level of ER was positively correlated with the sensitivity of the endocrine therapy and could predict tamoxifen resistance in breast cancer [29]. However, ER-positive patients are less chemosensitive than ER-negative cases [30] so that adjuvant chemotherapy might not be beneficial to some ER-positive breast tumors [11]. And ER-positive patients also have distinct behaviors and outcome due to different molecular features. Thus, a biomarker which could accurately predict clinical outcome in ER-positive patients with breast cancer is needed urgently.

In the present study, we used miRNA expression microarray data from TCGA and divided the data into two

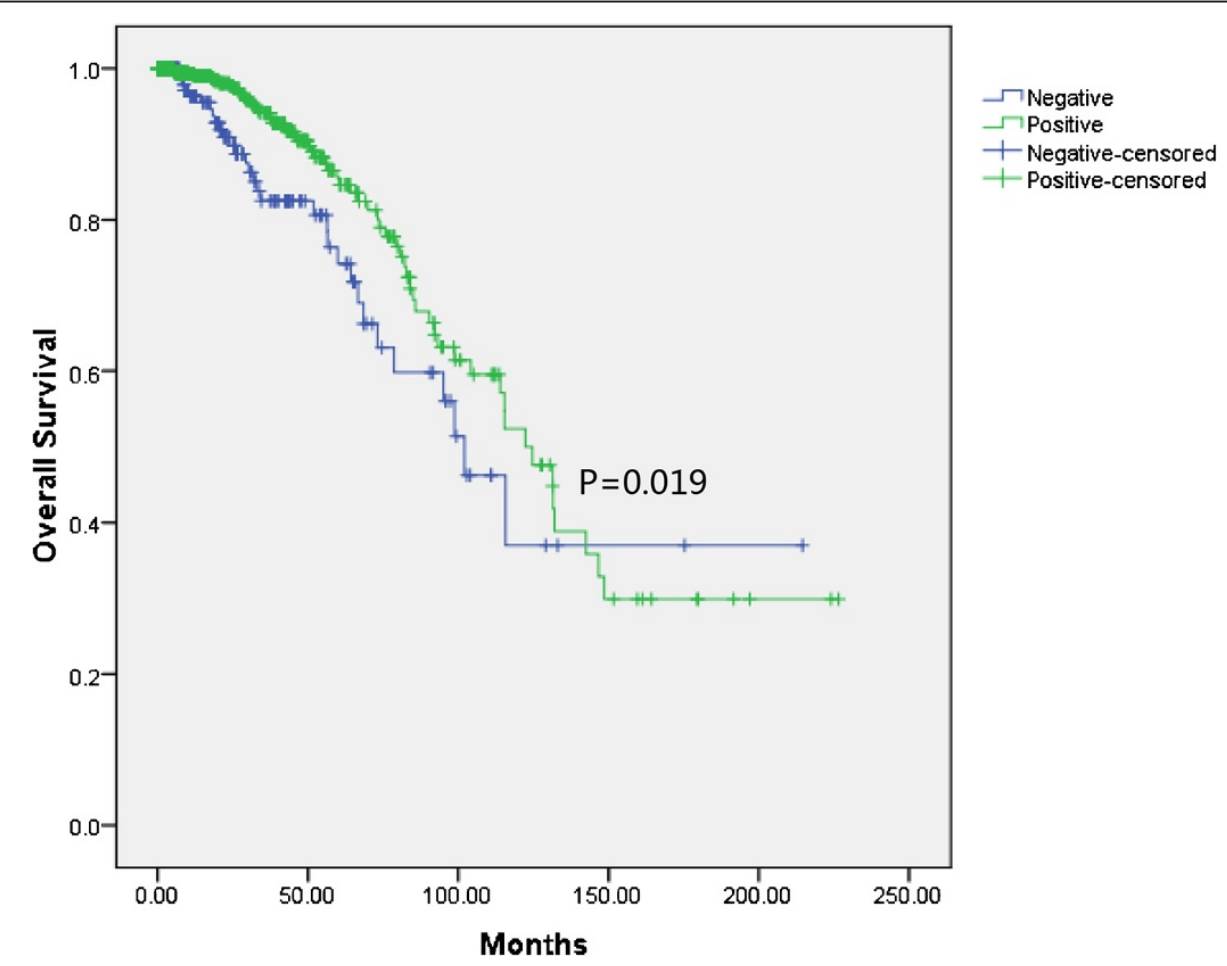

Figure 2 Overall survival of breast cancer in the combined cohorts according to the status of ER. 


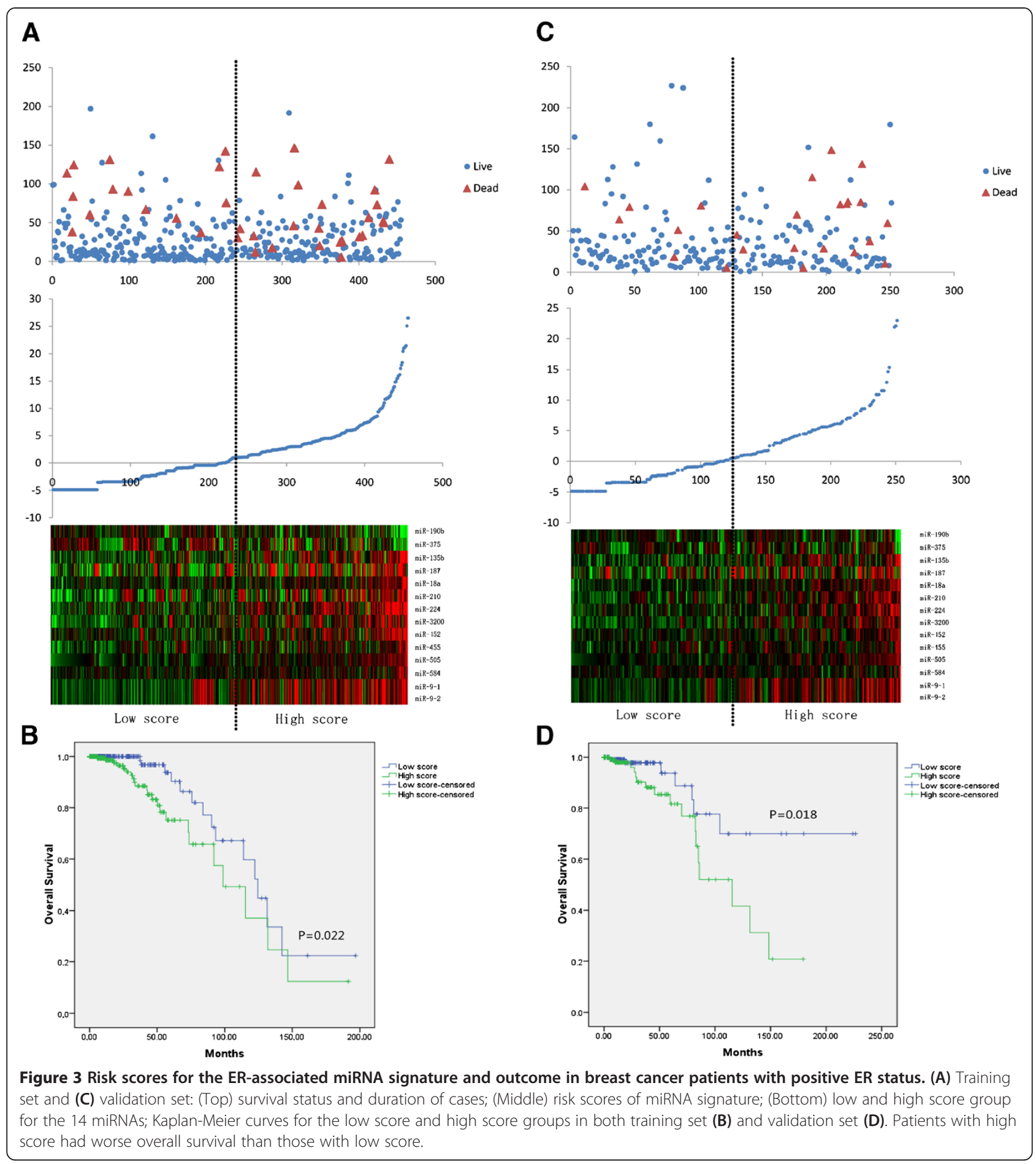

cohorts based on the cases from two sequencing platforms. Following the strategy of using the larger cohort as training set, and the smaller one as the validation set [31], we identified 14 miRNAs which were significantly associated with the status of ER both in training and validation set. The optimal cutoff value for each miRNA to discriminate different status of ER was determined by ROC curve.
The risk score calculated from expression of each miRNA weighted by regression coefficient B fitted with status of ER might reflect the tendency from positive to negative status of ER. High score might be more likely related to negative status while low score to positive status. To assess the prognostic value of the miRNA signature, the ER-positive cases were divided into high and low score 
groups according to the risk score. Twelve miRNAs upregulated in ER-negative breast cancer patients exhibited high expression in high score group and two declined miRNAs showed high expression level in low score group. And the ER-positive patients in high score group suffered poorer survival compared with low score group both in the training stage and validation set.

Lowery et al. [32] found that a 6-miRNA signature could predict status of ER, of which only miR-135b was consistently included in the 14-miRNA signature in our study. To some extent, difference of target population and/or the entry criteria might be responsible for the phenomenon. However, it was also reported that elevated miR-18a [33], miR-505 [34], miR-9 and reduced miR-375 [35] were correlated to oestrogen receptor negativity. The results were consistent with our findings. In addition, re-expression of miR-375 could reverse tamoxifen resistance and epithelialmesenchymal transition-like properties in the established tamoxifen-resistant breast cancer cells [36]. Moreover, high expression of miR-187 in breast cancer could lead to a more aggressive, invasive phenotype and may act as an independent predictor of outcome [37]. Prognostic value of miR-210 has been explored in many cancer types. Breast cancer patients with elevated miR-210 might have a poor outcome [38,39]. Huang et al. [40] found that miR-224 might act as an oncogene by directly suppressing the RKIP tumor suppressor resulting in promoting metastasis of breast cancer. A higher expression of miR-9 is associated with lymph node metastasis [41] and could act as a predictor for local recurrence of breast cancer [35]. However, the other 5 miRNAs were not explored so widely in breast cancer and further researches are required to investigate their complex molecular mechanisms.

The specificity of biomarkers based on a single miRNA is generally poor [25]. Thus, we developed a risk score of combination the 14 miRNAs associated with ER status and multiplied their corresponding weight to survival and found that the score could predict overall survival in ER-positive patients. Better insights into the mechanism of the 14-miRNA signature in breast cancer might contribute to an understanding of the genetic aberrations that are involved in tumor genesis, progression and response to treatment.

In conclusion, the ER associated miRNA signature identified in our study might support a potential predictor to indicate clinical outcome for ER-positive patients and serve as potential molecular targets for new therapeutic strategies, subsequently leading to improved outcomes.

\section{Additional file}

Additional file 1: Figure S1. ROC curve analyses of 14 miRNAs for patients with different status of ER.

\section{Competing interests}

The authors declare that they have no competing interest.

\section{Authors' contributions}

ZX, WXP, HZB carried out the molecular genetic studies. ZX, XL, ZW participated in the sequence alignment. $Z X, L P$ drafted the manuscript. All authors read and approved the final manuscript.

\section{Acknowledgments}

This study was supported by the National Natural Science Foundation of China (Grant number: 81171908 ) and Jiangsu Province Clinical science and technology projects (Clinical Research Center, BL2012008).

\section{Author details}

${ }^{1}$ Department of Oncology, First Affiliated Hospital of Nanjing Medical University, 300 Guangzhou Road, Nanjing 210029, China. ${ }^{2}$ Cancer Center of Nanjing Medical University, Nanjing 210029, China. ${ }^{3}$ Key Laboratory of Human Functional Genomics of Jiangsu Province, Clinical Diabetes Centre of Jiangsu Province, Nanjing Medical University, Nanjing 210029, China. ${ }^{4}$ Department of Thoracic Surgery, The Affiliated Jiangning Hospital of Nanjing Medical University, Nanjing 210029, China.

Received: 27 July 2014 Accepted: 27 October 2014

Published online: 06 November 2014

\section{References}

1. Parker JS, Mullins M, Cheang MC, Leung S, Voduc D, Vickery T, Davies S, Fauron C, He X, Hu Z, Quackenbush JF, Stijleman IJ, Palazzo J, Marron JS, Nobel AB, Mardis E, Nielsen TO, Ellis MJ, Perou CM, Bernard PS: Supervised risk predictor of breast cancer based on intrinsic subtypes. J Clin Oncol 2009, 27:1160-1167.

2. Sorlie T, Perou CM, Tibshirani R, Aas T, Geisler S, Johnsen H, Hastie T, Eisen MB, van de Rijn M, Jeffrey SS, Thorsen T, Quist H, Matese JC, Brown PO, Botstein D, Lonning PE, Borresen-Dale AL: Gene expression patterns of breast carcinomas distinguish tumor subclasses with clinical implications. Proc Natl Acad Sci U S A 2001, 98:10869-10874.

3. Potti A, Dressman HK, Bild A, Riedel RF, Chan G, Sayer R, Cragun J, Cottrill H, Kelley MJ, Petersen R, Harpole D, Marks J, Berchuck A, Ginsburg GS, Febbo $P$, Lancaster J, Nevins JR: Genomic signatures to guide the use of chemotherapeutics. Nat Med 2006, 12:1294-1300.

4. Yin ZQ, Liu JJ, Xu YC, Yu J, Ding GH, Yang F, Tang L, Liu BH, Ma Y, Xia YW, Lin $X L$, Wang $H X$ : A 41-gene signature derived from breast cancer stem cells as a predictor of survival. J Exp Clin Cancer Res 2014, 33:49.

5. Yang Y, Zhang Y, Wu Q, Cui X, Lin Z, Liu S, Chen L: Clinical implications of high NQO1 expression in breast cancers. J Exp Clin Cancer Res 2014, 33:14.

6. Zhang X, Min J, Wang Y, Li Y, Li H, Liu Q, Liang X, Mu P: RABEX-5 plays an oncogenic role in breast cancer by activating MMP-9 pathway. J Exp Clin Cancer Res 2013, 32:52.

7. Bartlett JM, Brookes CL, Robson T, van de Velde CJ, Billingham L, Campbell FM, Grant M, Hasenburg A, Hille ET, Kay C, Kieback DG, Putter H, Markopoulos C, Kranenbarg EM, Mallon EA, Dirix L, Seynaeve C, Rea D: Estrogen receptor and progesterone receptor as predictive biomarkers of response to endocrine therapy: a prospectively powered pathology study in the Tamoxifen and Exemestane Adjuvant Multinational trial. J Clin Oncol 2011, 29:1531-1538.

8. Purdie CA, Quinlan P, Jordan LB, Ashfield A, Ogston S, Dewar JA, Thompson AM: Progesterone receptor expression is an independent prognostic variable in early breast cancer: a population-based study. Br J Cancer 2014, 110:565-572.

9. Rimawi MF, Mayer IA, Forero A, Nanda R, Goetz MP, Rodriguez AA, Pavlick AC, Wang T, Hilsenbeck SG, Gutierrez C, Schiff R, Osborne CK, Chang JC: Multicenter phase II study of neoadjuvant lapatinib and trastuzumab with hormonal therapy and without chemotherapy in patients with human epidermal growth factor receptor 2-overexpressing breast cancer: TBCRC 006. J Clin Oncol 2013, 31:1726-1731.

10. Carey LA, Perou CM, Livasy CA, Dressler LG, Cowan D, Conway K, Karaca G, Troester MA, Tse CK, Edmiston S, Deming SL, Geradts J, Cheang MC, Nielsen TO, Moorman PG, Earp HS, Millikan RC: Race, breast cancer subtypes, and survival in the Carolina Breast Cancer Study. JAMA 2006, 295:2492-2502.

11. Nishio M, Naoi Y, Tsunashima R, Nakauchi C, Kagara N, Shimoda M, Shimomura A, Maruyama N, Shimazu K, Kim SJ, Noguchi S: 72-Gene classifier for predicting prognosis of estrogen receptor-positive and 
node-negative breast cancer patients using formalin-fixed, paraffinembedded tumor tissues. Clin Breast Cancer 2013, 14:e73-80.

12. Lee RC, Feinbaum RL, Ambros V: The C. elegans heterochronic gene lin- 4 encodes small RNAs with antisense complementarity to lin-14. Cell 1993, 75:843-854

13. Lewis BP, Burge CB, Bartel DP: Conserved seed pairing, often flanked by adenosines, indicates that thousands of human genes are microRNA targets. Cell 2005, 120:15-20.

14. Carrington JC, Ambros V: Role of microRNAs in plant and animal development. Science 2003, 301:336-338.

15. Suarez Y, Sessa WC: MicroRNAs as novel regulators of angiogenesis. Circ Res 2009, 104:442-454.

16. Xu P, Guo M, Hay BA: MicroRNAs and the regulation of cell death. Trends Genet 2004, 20:617-624.

17. Bartel DP, Chen CZ: Micromanagers of gene expression: the potentially widespread influence of metazoan microRNAs. Nat Rev Genet 2004, 5:396-400.

18. Zhang JX, Song W, Chen ZH, Wei JH, Liao YJ, Lei J, Hu M, Chen GZ, Liao B, Lu J, Zhao HW, Chen W, He YL, Wang HY, Xie D, Luo JH: Prognostic and predictive value of a microRNA signature in stage II colon cancer: a microRNA expression analysis. Lancet Oncol 2013, 14:1295-1306.

19. Liu N, Chen NY, Cui RX, Li WF, Li Y, Wei RR, Zhang MY, Sun Y, Huang BJ, Chen M, He QM, Jiang N, Chen L, Cho WC, Yun JP, Zeng J, Liu LZ, Li L, Guo Y, Wang HY, Ma J: Prognostic value of a microRNA signature in nasopharyngeal carcinoma: a microRNA expression analysis. Lancet Oncol 2012, 13:633-641.

20. Fan $M Q$, Huang $C B, G u$ Y, Xiao Y, Sheng JX, Zhong L: Decrease expression of microRNA-20a promotes cancer cell proliferation and predicts poor survival of hepatocellular carcinoma. J Exp Clin Cancer Res 2013, 32:21.

21. Wang Q, Li P, Li A, Jiang W, Wang H, Wang J, Xie K: Plasma specific miRNAs as predictive biomarkers for diagnosis and prognosis of glioma. J Exp Clin Cancer Res 2012, 31:97.

22. Kandoth C, McLellan MD, Vandin F, Ye K, Niu B, Lu C, Xie M, Zhang $\mathrm{Q}$ McMichael JF, Wyczalkowski MA, Leiserson MD, Miller CA, Welch JS, Walter MJ, Wendl MC, Ley TJ, Wilson RK, Raphael BJ, Ding L: Mutational landscape and significance across 12 major cancer types. Nature 2013, 502:333-339.

23. Volinia S, Croce CM: Prognostic microRNA/mRNA signature from the integrated analysis of patients with invasive breast cancer. Proc Natl Acad SciU S A 2013, 110:7413-7417.

24. Simon R, Lam A, Li MC, Ngan M, Menenzes S, Zhao Y: Analysis of gene expression data using BRB-ArrayTools. Cancer Inform 2007, 3:11-17.

25. Liu R, Zhang C, Hu Z, Li G, Wang C, Yang C, Huang D, Chen X, Zhang H, Zhuang R, Deng T, Liu H, Yin J, Wang S, Zen K, Ba Y, Zhang CY: A five-microRNA signature identified from genome-wide serum microRNA expression profiling serves as a fingerprint for gastric cancer diagnosis. Eur J Cancer 2011, 47:784-791.

26. DeSantis C, Siegel R, Bandi P, Jemal A: Breast cancer statistics, 2011. CA Cancer J Clin 2011, 61:409-418.

27. Jorns JM, Healy P, Zhao L: Review of estrogen receptor, progesterone receptor, and HER-2/neu immunohistochemistry impacts on treatment for a small subset of breast cancer patients transferring care to another institution. Arch Pathol Lab Med 2013, 137:1660-1663.

28. Berry DA, Cirrincione C, Henderson IC, Citron ML, Budman DR, Goldstein $\sqcup$, Martino S, Perez EA, Muss HB, Norton L, Hudis C, Winer EP: Estrogenreceptor status and outcomes of modern chemotherapy for patients with node-positive breast cancer. JAMA 2006, 295:1658-1667.

29. Esslimani-Sahla M, Simony-Lafontaine J, Kramar A, Lavaill R, Mollevi C, Warner M, Gustafsson JA, Rochefort H: Estrogen receptor beta (ER beta) level but not its ER beta cx variant helps to predict tamoxifen resistance in breast cancer. Clin Cancer Res 2004, 10:5769-5776.

30. Colleoni M, Viale G, Zahrieh D, Pruneri G, Gentilini O, Veronesi P, Gelber RD, Curigliano G, Torrisi R, Luini A, Intra M, Galimberti V, Renne G, Nole F, Peruzzotti G, Goldhirsch A: Chemotherapy is more effective in patients with breast cancer not expressing steroid hormone receptors: a study of preoperative treatment. Clin Cancer Res 2004, 10:6622-6628.

31. Li R, Qian J, Wang YY, Zhang JX, You YP: Long noncoding RNA profiles reveal three molecular subtypes in Glioma. CNS Neurosci Ther 2014, 20:339-343.

32. Lowery AJ, Miller N, Devaney A, McNeill RE, Davoren PA, Lemetre C, Benes V, Schmidt S, Blake J, Ball G, Kerin MJ: MicroRNA signatures predict oestrogen receptor, progesterone receptor and HER2/neu receptor status in breast cancer. Breast Cancer Res 2009, 11:R27.
33. Yoshimoto $N$, Toyama T, Takahashi S, Sugiura H, Endo Y, Iwasa M, Fujii $Y$, Yamashita H: Distinct expressions of microRNAs that directly target estrogen receptor alpha in human breast cancer. Breast Cancer Res Treat 2011, 130:331-339.

34. Jonsdottir K, Janssen SR, Da Rosa FC, Gudlaugsson E, Skaland I, Baak JP, Janssen EA: Validation of expression patterns for nine miRNAs in 204 lymph-node negative breast cancers. PLoS One 2012, 7:e48692.

35. Zhou X, Marian C, Makambi KH, Kosti O, Kallakury BV, Loffredo CA, Zheng YL: MicroRNA-9 as potential biomarker for breast cancer local recurrence and tumor estrogen receptor status. PLoS One 2012, 7:e39011.

36. Ward A, Balwierz A, Zhang JD, Kublbeck M, Pawitan Y, Hielscher T, Wiemann S, Sahin O: Re-expression of microRNA-375 reverses both tamoxifen resistance and accompanying EMT-like properties in breast cancer. Oncogene 2013, 32:1173-1182.

37. Mulrane L, Madden SF, Brennan DJ, Gremel G, McGee SF, McNally S, Martin F, Crown JP, Jirstrom K, Higgins DG, Gallagher WM, O Connor DP: miR-187 is an independent prognostic factor in breast cancer and confers increased invasive potential in vitro. Clin Cancer Res 2012, 18:6702-6713.

38. Wang J, Zhao J, Shi M, Ding Y, Sun H, Yuan F, Zou Z: Elevated expression of miR-210 predicts poor survival of cancer patients: a systematic review and meta-analysis. PLoS One 2014, 9:e89223.

39. Qin Q, Furong W, Baosheng L: Multiple functions of hypoxia-regulated miR-210 in cancer. J Exp Clin Cancer Res 2014, 33:50.

40. Huang L, Dai T, Lin X, Zhao X, Chen X, Wang C, Li X, Shen H, Wang X: MicroRNA-224 targets RKIP to control cell invasion and expression of metastasis genes in human breast cancer cells. Biochem Biophys Res Commun 2012, 425:127-133.

41. Wang J, Zhao H, Tang D, Wu J, Yao G, Zhang Q: Overexpressions of microRNA-9 and microRNA-200c in human breast cancers are associated with lymph node metastasis. Cancer Biother Radiopharm 2013, 28:283-288.

\section{doi:10.1186/s13046-014-0094-5}

Cite this article as: Zhou et al: An ER-associated miRNA signature predicts prognosis in ER-positive breast cancer. Journal of Experimental \& Clinical Cancer Research 2014 33:94.

\section{Submit your next manuscript to BioMed Central and take full advantage of:}

- Convenient online submission

- Thorough peer review

- No space constraints or color figure charges

- Immediate publication on acceptance

- Inclusion in PubMed, CAS, Scopus and Google Scholar

- Research which is freely available for redistribution
C Biomed Central 